Received 09/19/2018

Review began 09/21/2018

Review ended 09/22/2018

Published 09/26/2018

(C) Copyright 2018

Itani et al. This is an open access article distributed under the terms of the Creative Commons Attribution License CC-BY 3.0., which permits unrestricted use, distribution, and reproduction in any medium, provided the original author and source are credited.

\title{
Pregnancy with Takayasu's Arteritis: A Case Report and Literature Review
}

Rayan Itani ${ }^{1}$, Naela Elmallahi ${ }^{1}$, Mohamed Ahmed Abdelmoneam Ramadan ${ }^{1}$, Abdullah Al Ibrahim $^{2}$

1. Obstetrics and Gynecology, Women's Wellness and Research Center/ Hamad Medical Corporation, Doha, QAT 2. Obstetrics and Gynecology, Women's Wellness and Research Center/ Hamad Medical Corporation, Doha, QAT

$\nabla$ Corresponding author: Rayan Itani, rayanaitani91@gmail.com Disclosures can be found in Additional Information at the end of the article

\section{Abstract}

Takayasu's arteritis (TA) is a rare and chronic inflammatory disease of the large vessels. It affects women of reproductive age and leads to an increased risk of cardiovascular complications, such as hypertension and congestive heart failure. We are presenting a case of a pregnant woman with TA, who was seen and managed at a tertiary care institute and ultimately enjoyed a favorable outcome. Thus, multidisciplinary care for patients with TA has proven to be crucial in optimized and favorable maternal and fetal/neonatal outcomes.

Categories: Obstetrics/Gynecology

Keywords: takayasu's arteritis, pregnancy, women hospital, qatar

\section{Introduction}

Takayasu's arteritis (TA), also known as “young female arteritis,” is a rare and chronic inflammatory disease of the large vessels. The disease mainly affects women of reproductive age and Asian origin [1]. Moreover, TA leads to several complications including occlusion as well as aneurysm formation in systemic and pulmonary arteries. During pregnancy, there is an increased risk of cardiovascular complications such as hypertension and congestive heart failure [2]. However, evidence remains scarce on the appropriate management of the disease despite its harmful impact on maternal and neonatal health. Moreover, the literature supports the need for an interdisciplinary approach to optimize the care of such patients [3].

\section{Case Presentation}

A 31-year-old woman, of Indian origin and known to have TA, was booked for an antenatal care appointment at the 11th week of her third gestation in April 2017. Her earlier two pregnancies in 2008 and 2010 resulted in the normal vaginal delivery of a full term and healthy singleton each. However, her second pregnancy was complicated by pre-eclampsia. The patient was incidentally diagnosed through a routine chest X-ray, which revealed a widened superior mediastinum (Figure 1) in June 2014. 


\section{Cureus}

FIGURE 1: X-ray showing widened mediastinum, 2014.

Further physical examination revealed an absent left radial pulse. Subsequently, a computed tomography (CT) pulmonary angiogram confirmed the presence of a dissecting aortic aneurysm, which measured $7 \mathrm{~cm}$ in length and was inferior to the origin of the left subclavian artery (occluded) (Figure 2). The CT scan also revealed an atrophic right kidney and a hypertrophied left one. Thus, the patient was placed on prednisone as well as methotrexate and booked for endovascular repair surgery. The woman later successfully underwent endovascular stent grafting of the thoracic aorta in April 2015. After developing pneumonia, the patient was switched from methotrexate to azathioprine (AZA) and maintained on amlodipine (5 mg), aspirin, and prednisone. 


\section{Cureus}
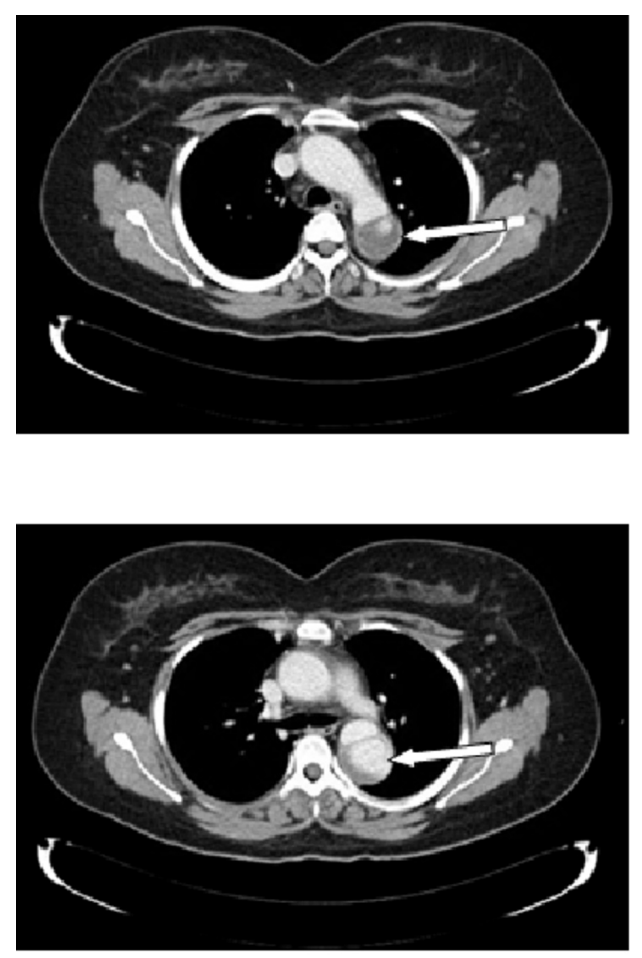
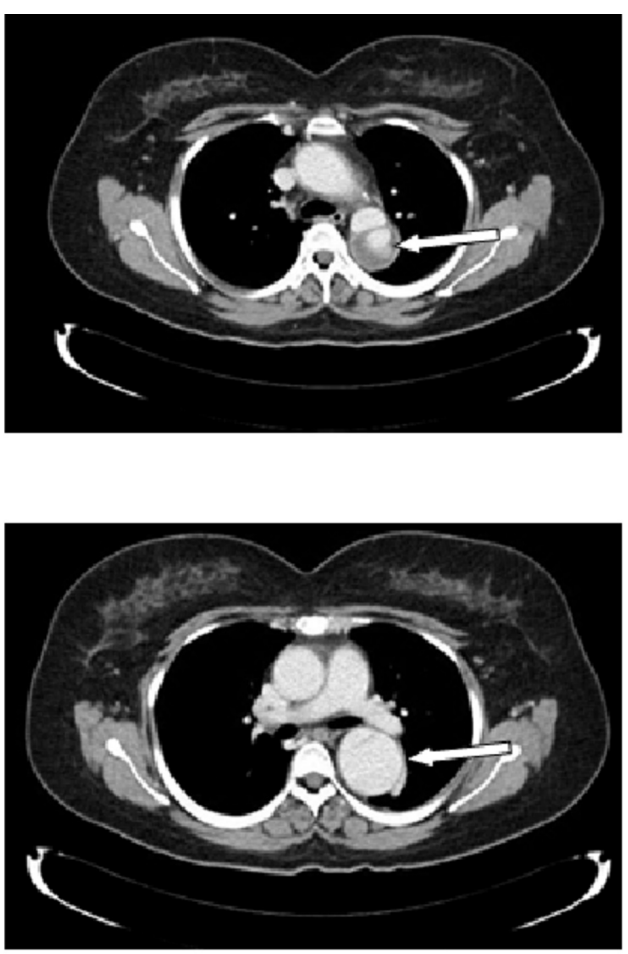

\section{FIGURE 2: Computed tomography (CT) scan showing a dissecting aortic aneurysm (white arrow), 2014.}

The lady's antenatal care was under the feto-maternal unit (FMU) at the Women's Hospital. Simultaneously, the patient was regularly followed by her rheumatologist and vascular surgeon. The patient resumed her medication during pregnancy; and serial ultrasound scans revealed a normally developing fetus. The antenatal period was uneventful except for gestational diabetes mellitus. In November 2017, the patient presented at 38+ weeks gestation for an elective cesarean section and bilateral tubal ligation as advised by the multidisciplinary team. Thus, the patient delivered a healthy baby girl, weighing $2279 \mathrm{~g}$, and her postpartum period was uneventful. The patient was counselled about breastfeeding while on AZA and told that the current evidence does not suggest any risk from AZA during pregnancy and while breastfeeding. One month following her delivery, the patient presented for a follow-up appointment with her vascular surgeon and was asymptomatic. Also, her blood pressure (BP) measurement and inflammatory markers were within the normal range.

\section{Discussion}

Women account for $80 \%-90 \%$ of TA cases and the age of onset is usually between 10 and 40 years [4-5]. The disease has a worldwide distribution, with the greatest prevalence being in Asia [6]. Furthermore, Japan reported an estimated 150 new cases of TA each year [7]. On the other hand, the incidence of TA in the United States and Europe is one to three new cases per year per million population [5].

Takayasu's arteritis is a chronic inflammatory disease that involves the aorta, its branches, and the pulmonary arteries $[6,8]$. The inflammation results in varying degree of stenosis, occlusion, or dilatation of the involved vessels. The etiology and the precise pathogenesis of TA are still unknown; however, much has been learnt about the disease since its initial description by M. Takayasu, a Japanese ophthalmologist, in 1908 [9-10]. Moreover, the symptoms range from fever, fatigue, and weight loss to life-threatening hemoptysis and heart failure. The 
management of TA is a multidisciplinary approach with the involvement of obstetricians, anesthesiologists, cardiologists, rheumatologists, and neonatologists. Ultimately, the aims encompass the control of inflammation, prevention, and treatment of complications like hypertension and occlusive or stenotic lesions [11].

When managing women of reproductive age with TA, preconception counseling is essential. In addition, such counseling will focus mainly on dosage adjustment, cessation of cytotoxic drugs, folic acid supplementation in the periconception period, and the optimal timing of pregnancy. Similarly, the pregnancy should be ideally planned in remission phase and patients are encouraged to pursue an early booking for regular antenatal supervision. In addition to routine antenatal visits, serial monitoring of BP, renal function, cardiac status, and pre-eclamptic screening is vital in such patients. Furthermore, fetal surveillance is also necessary and will include daily fetal kick count, gravidogram, serial fetal biometry, biophysical profile, and fetal Doppler [12].

In addition to that, pregnancy does not interfere with the disease progression of TA [13-14]. However, BP control is of paramount importance as any increase might rupture an aneurysm, induce hypotension, and lead to cerebral ischemia in the mother. Moreover, peripheral BP monitoring may not be accurate and might complicate the treatment of hypertension in these patients. Most patients benefit from invasive BP monitoring or the measurement of peripheral $\mathrm{BP}$ in multiple extremities because the upper extremity pulses may be absent [15].

Also, controlling BP during pregnancy may be difficult due to the physiological changes in this period. Thus, any patient with TA should plan to conceive when the BP and disease are stable. It is also vital to adjust the antihypertensive medication and avoid angiotensin-converting enzyme inhibitors or angiotensin inhibitors. On the other hand, uncontrolled hypertension during pregnancy has been associated with abortion, stillbirths, aortic dissection, cardiac and renal insufficiency, stroke, and maternal death [16-18]. Finally, vaginal delivery has proven to be the preferred mode of labor management for patients with TA. Additionally, epidural analgesia has been advocated for labor and delivery as well.

\section{Conclusions}

The current case adds further evidence to the medical management of TA during pregnancy. As reported earlier, the incidence of TA is the highest during childbearing age, but there appears to be no exacerbating effect of pregnancy on the natural history of TA. Multidisciplinary care for patients with TA has proven crucial to reach optimized and favorable maternal and fetal/neonatal outcomes.

\section{Additional Information}

\section{Disclosures}

Human subjects: Consent was obtained by all participants in this study. Conflicts of interest: In compliance with the ICMJE uniform disclosure form, all authors declare the following:

Payment/services info: All authors have declared that no financial support was received from any organization for the submitted work. Financial relationships: All authors have declared that they have no financial relationships at present or within the previous three years with any organizations that might have an interest in the submitted work. Other relationships: All authors have declared that there are no other relationships or activities that could appear to have influenced the submitted work.

\section{References}

1. Matsumura A, Moriwaki R, Numano F: Pregnancy in Takayasu arteritis from the view of 
internal medicine. Heart Vessels Suppl. 1992, 7:120-124.

2. Soo-Hoo S, Seong J, Porten B, Skeik N: Challenges of Takayasu arteritis in pregnancy: a case report. Vasc Endovascular Surg. 2017, 51:195-198. 10.1177/1538574417698904

3. Koster M, Matteson E, Warrington K: Recent advances in the clinical management of giant cell arteritis and Takayasu arteritis. Curr Opin Rheumatol. 2016, 28:211-217. 10.1097/BOR.0000000000000265

4. Lupi-Herrera E, Sánchez-Torres G, Marcushamer J, Mispireta J, Horwitz S, Vela JE: Takayasu's arteritis. Clinical study of 107 cases. Am Heart J. 1977, 93:94-103. 10.1016/S00028703(77)80178-6

5. Arend WP, Michel BA, Bloch DA, et al.: The American College of Rheumatology 1990 Criteria for the classification of Takayasu arteritis. Arthritis Rheum. 1990, 33:1129-1134. 10.1002/art.1780330811

6. Dabague J, Reyes PA: Takayasu arteritis in Mexico: a 38-year clinical perspective through literature review. Int J Cardiol. 1996, 54:103-109. 10.1016/0167-5273(96)02642-3

7. Ishikawa K: Natural history and classification of occlusive thromboaortopathy (Takayasu's disease). Circulation. 1978, 57:27-35.

8. Koide K: Takayasu arteritis in Japan. Heart Vessels Suppl. 1992, 7:48-54.

9. Nasu T: Pathology of pulseless disease: a systematic study and critical review of twenty-one autopsy cases reported in Japan. Angiology. 1963, 14:225-242. 10.1177/000331976301400502

10. Takayasu M: Case with unusual changes of the central vessels in the retina (in Japanese) . Acta Soc Ophthal Jap. 1908, 12:554-555.

11. Marwah S, Rajput M, Mohindra R, Gaikwad H, Sharma M, Topden S: Takayasu's arteritis in pregnancy: a rare case report from a tertiary care infirmary in India. Case Rep Obstet Gynecol. 2017, 1-6. 10.1155/2017/2403451

12. Papandony MC, Brady SR, Aw TJ : Vasculitis or fibromusculardysplasia?. Med J Aust. 2015, 202:100-101. 10.5694/mja14.00224

13. Koster MJ, Matteson EL, Warrington KJ: Recent advances in the clinical management of giant cell arteritis and Takayasu arteritis. Curr Opin Rheumatol. 2016, 28:211-217. 10.1097/BOR.0000000000000265

14. Ishikawa K, Maetani S: Long-term outcome for 120 Japanese patients with Takayasu's disease. Clinical and statistical analyses of related prognostic factors. Circulation. 1994, 90:1855-1860.

15. Winn HN, Setaro JF, Mazor M, Reece EA, Black HR, Hobbins JC: Severe Takayasu's arteritis in pregnancy: the role of central hemodynamic monitoring. Am J Obstet Gynecol. 1988, 159:1135-1136.

16. Lakhi NA, Jones J: Takayasu's arteritis in pregnancy complicated by peripartum aortic dissection. Arch Gynecol Obstet. 2010, 282:103-106. 10.1007/s00404-009-1315-6

17. Mandal D, Mandal S, Dattaray C, et al.: Takayasu arteritis in pregnancy: an analysis from eastern India. Arch Gynecol Obstet. 2012, 285:567-571. 10.1007/s00404-011-1998-3

18. Suri V, Aggarwal N, Keepanasseril A, Chopra S, Vijayvergiya R, Jain S: Pregnancy and Takayasu arteritis: a single centre experience from North India. J Obstet Gynaecol Res. 2010, 36:519-524. 10.1111/j.1447-0756.2010.01226.x 